\title{
FOX: A friendly tool to solve nonmolecular structures from powder diffraction
}

\author{
Radovan Černýa) \\ Laboratoire de Cristallographie, Université de Genève, 24, quai Ernest-Ansermet, \\ CH-1211 Genève 4, Switzerland \\ Vincent Favre-Nicolin \\ Université Joseph Fourier and CEA, DRFMC/SP2M/NRS, 17, rue des Martyrs, \\ F-38054 Grenoble Cedex 9, France
}

(Received 21 July 2005; accepted 12 October 2005)

\begin{abstract}
Structural characterization from powder diffraction of compounds not containing isolated molecules but three-dimensional infinite structure (alloys, intermetallics, framework compounds, extended solids) by direct space methods has been largely improved in the last 15 years. The success of the method depends very much on a proper modeling of the structure from building blocks. The modeling from larger building blocks improves the convergence of the global optimization algorithm by a factor of up to 10 . However, care must be taken about the correctness of the building block, like its rigidity, deformation, bonding distances, and ligand identity. Dynamical occupancy correction implemented in the direct space program FOX has shown to be useful when merging excess atoms, and even larger building blocks like coordination polyhedra. It also allows joining smaller blocks into larger ones in the case when the connectivity was not a priori evident from the structural model. We will show in several examples of nonmolecular structures the effect of the modeling by correct structural units. (C) 2005 International Centre for Diffraction Data. [DOI: 10.1154/1.2135314]
\end{abstract}

Key words: powder diffraction, structure solution, direct space method, simulated annealing

\section{INTRODUCTION}

Powder diffraction using X-rays and neutrons plays a major role in the search for new materials which are not available in the form of single crystals. Moreover, most of the industrial applications of inorganic and organic compounds are in the form of polycrystalline materials (for example, metal hydrides for storage and battery applications, metallic and intermetallic compounds in industry, thin films, organic compounds in pharmaceutical industry, etc.). Diffraction methods on powders are more difficult than on single crystals, because the available data are a projection of three-dimensional diffraction pattern to one dimension, and consequently the diffraction peaks are overlapped. The power of powder diffraction methods was considerably improved after the construction of high resolution powder diffractometers at the last generation synchrotron sources and neutron sources.

The methods of crystal structure determination from powder diffraction (SDPD) can be divided into two groups according to the working space [David et al. (2002) and references therein].

(1) Reciprocal space methods: They use procedures developed for single crystal data like direct method, Patterson synthesis or maximum entropy, and optimized for powder data. They need structure factor amplitudes obtained by powder pattern decomposition.

(2) Direct space methods: Different algorithms for a search in the direct space of structural parameters are used, and an agreement factor between the observed and calculated

\footnotetext{
${ }^{a)}$ Electronic mail: radovan.cerny @ cryst.unige.ch
}

powder diffraction data is evaluated, and the structural model is optimized to improve the agreement.

The extraction of structure factor amplitudes can be complicated by a strong overlapping of peaks in the diffraction pattern because of their broadening (often anisotropic) because of the crystal lattice defects. Two alternative solutions of this problem exist: either direct space methods, which do not need the extraction of the structure factor amplitudes, or improvement of the pattern decomposition. When designing the program FOX, we have chosen the first option.

At the end of the last century the direct space methods were developing intensively in the field of molecular crystals. Significantly less activity was found in the domain of nonmolecular (inorganic) crystals. However, the idea of constructing the crystal structure from well-defined building blocks, like molecules in the case of molecular crystals, can be applied also to the nonmolecular crystals like extended solids or framework structures. And this was the main idea behind FOX (Favre-Nicolin and Černý, 2002), which has become a friendly tool for solving not only nonmolecular but also the molecular structures from powder diffraction data. This review summarizes the results obtained in different laboratories when solving nonmolecular crystal structures with FOX since its release on the ECM-20 in 2001, until now. The results obtained on molecular crystals will be a subject of another review.

\section{STRUCTURAL BUILDING BLOCKS}

When designing FOX we wanted to allow it to work with a wide variety of different types of compounds. Any crystal 


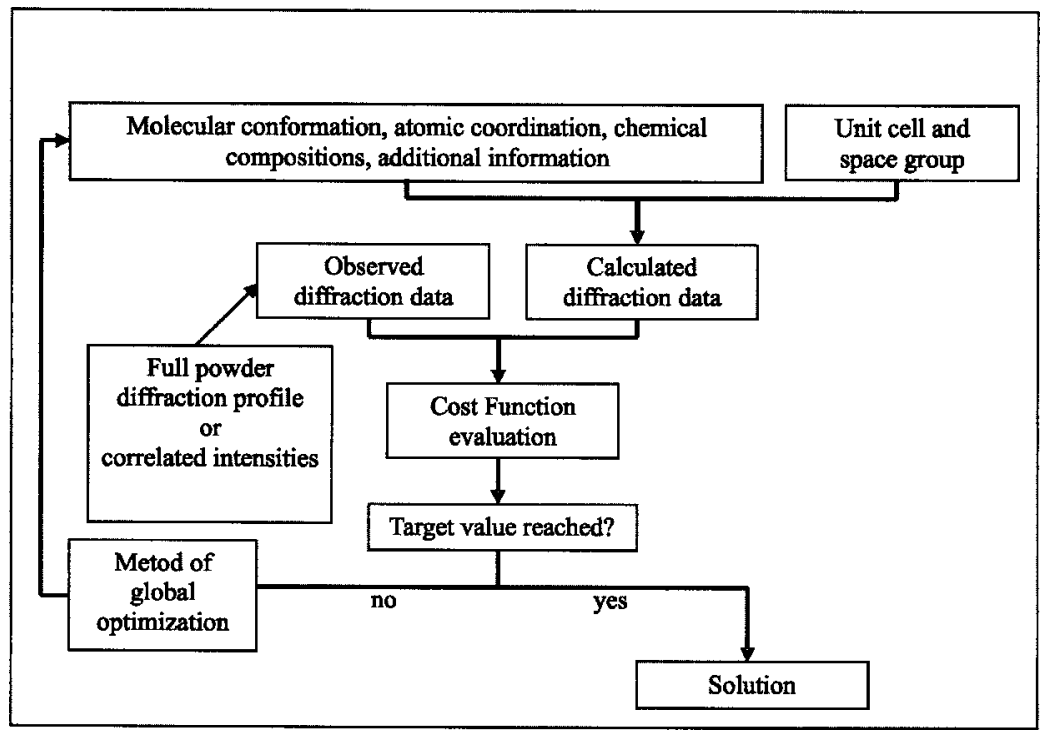

Figure 1. A flow chart representing a typical implementation (like in FOx) of the global optimization approach to the crystal structure solution from powder diffraction data.

structure can be described as a combination of scattering objects, which can be independent atoms, molecules, polyhedra, or molecular fragments like amino acids. The advantage is that by a suitable choice of geometrical descriptors that characterize the crystal structure the number of free parameters to optimize, degree of freedom (DOF), can be decreased. There are numerous ways of describing a molecule, but one of the most useful is the internal coordinate description coded in $Z$ matrices (Shankland, 2004) that is widely used in molecular modeling. This information takes the form of the connectivity of the molecule under investigation; molecules are typically parametrized as a series of known bond lengths, known bond angles, and a mixture of known and unknown torsion angles (also called dihedral angles). The parametrization of molecules in terms of internal coordinates and external DOF (position and orientation of the molecule within the unit cell) has proven to be very successful in the context of SDPD.

The nonmolecular crystals can be built up from different building blocks like coordination polyhedra, monoatomic layers, or structural sheets of finite thickness. The easiest way is to construct the crystal structure, if possible, from coordination polyhedra. The type of atomic coordination in the nonmolecular crystals can be very often predicted from their chemical formula, cationic valence state, known structure of a similar compound and all available spectroscopic methods, locally sensitive, like NMR, EXAFS, Mössbauer spectroscopy, etc. A wide range of polyhedra is available in FOX (tetrahedron, octahedron, cube, prism, square plane, icosahedron), and these are naturally described using bond distances, angles, and dihedral angles. These were originally described using the $Z$ matrices as for molecules (Favre-Nicolin and Černý, 2002) to keep the uniform description for all building blocks in FOX. The description was later changed to the restraint-based approach to avoid some pitfalls of the $Z$ matrices (Favre-Nicolin and Černý, 2004), however, with less benefit for the nonmolecular compounds.

To describe a crystal structure adequately, it is necessary to take into account the possibility of corner-sharing between polyhedra, which is done in FOX by the dynamic occupancy correction (DOC) which also handles the special positions
(Favre-Nicolin and Černý, 2002). As will be demonstrated later DOC has revealed to be very powerful in the case when the exact composition of the studied compound is a priori not known exactly.

The description using the largest building blocks is vital in an ab initio structure determination process, since the number of trials required will (roughly) vary exponentially with the DOF (David et al., 2002). Describing the structure using building blocks consists of using all the a priori information about the connectivity of the atoms to reduce the DOF: e.g., a $\mathrm{PO}_{4}$ group requires six parameters (three translations + three rotations) as a tetrahedron, but 12 parameters if described as individual atoms. The number of DOF can generally be reduced by a factor of 2 for nonmolecular structures (Favre-Nicolin and Černý, 2002).

\section{GLOBAL OPTIMIZATION}

The direct space methods are based on location of building blocks in the elementary cell by using random moves and comparison of calculated and observed diffraction patterns and/or other cost functions (CF) like crystal energy, atomic coordination, etc., as a "fitness" of the current structural model. Generally said, it is a global optimization problem of a great complexity. Among the optimization algorithms Monte Carlo based simulated annealing (SA) [first applied to SDPD in Newsam et al. (1992)] and genetic algorithm (GA) [first applied to SDPD in Shankland et al. (1997)] are the most popular. A flow chart representing a typical implementation (like in FOX) of the global optimization approach to the crystal structure solution from powder diffraction data is given in Figure 1.

Any $\mathrm{CF}$ used in addition to the diffraction data can be valuable to find the correct structure, either to find the global minimum, or to disfavor unsound configurations and thus reduce the overall parameter space to be sampled. For the reason of a nonuniqueness of the energetic description of atomic interaction in crystal structures, discussed in more detail in Favre-Nicolin and Černý (2002), we have preferred to implement in FOX a simple antibump (AB) CF that adds a 
TABLE I. Nonmolecular structures solved by FOx from powder diffraction data. All the independent atoms (non- $\mathrm{H}$ and $\mathrm{H}$ ) in the asymmetric unit as given in the fourth and fifth columns were located by Fox with a few exceptions (see the text). The number of hydrogen atoms in parentheses means that they were not directly located from diffraction data, but the hydrogen positions were constrained from the molecule formula. HT means high temperature, LT low temperature, and HP high pressure phase. Data type: $\mathrm{X}-\mathrm{X}$-ray laboratory, $\mathrm{S}$ - synchrotron, $\mathrm{N}-$ neutron powder diffraction, $\mathrm{s}$ cryst- single crystal data.

\begin{tabular}{|c|c|c|c|c|c|}
\hline Formula & Symmetry & $\begin{array}{c}\text { Cell volume } \\
{\left[\AA^{3}\right]}\end{array}$ & $\begin{array}{l}\text { Non-H+ } \\
\mathrm{H} \text { atoms }\end{array}$ & Data & Reference \\
\hline \multicolumn{6}{|c|}{ Metal hydrides } \\
\hline $\mathrm{LiBH}_{4}-\mathrm{RT}$ & Pnma & 217 & $2+3$ & $\mathrm{~S}$ & Soulié et al., 2002 \\
\hline $\mathrm{LiBH}_{4}-\mathrm{HT}$ & $\mathrm{Pb}_{3} m c$ & 110 & $2+2$ & S & Soulié et al., 2002 \\
\hline $\mathrm{Li}_{3} \mathrm{AlD}_{6}$ & $R-3$ & 537 & $3+2$ & $\mathrm{~S}+\mathrm{N}$ & Brinks and Hauback, 2003 \\
\hline $\mathrm{NdNi}_{4} \mathrm{MgD}_{3.6}$ & $\operatorname{Pmn} 2_{1}$ & 205 & $5+3$ & $\mathrm{~S}+\mathrm{N}$ & Guénée et al., 2003 \\
\hline $\mathrm{CsMgD}_{3}$ & Pmmn & 522 & $4+5$ & $\mathrm{~S}+\mathrm{N}$ & Renaudin et al., 2003a \\
\hline $\mathrm{Zr}_{3} \mathrm{NiO}_{0.6} \mathrm{D}_{6.58}$ & Cmcm & 382 & $4+5$ & $\mathrm{~S}+\mathrm{N}$ & Zavalij, I. Yu. et al., 2003 \\
\hline $\mathrm{LaNi}_{2} \mathrm{Mn}_{3} \mathrm{D}_{5.6}$ & $P 6 / \mathrm{mmm}$ & 361 & $5+5$ & $\mathrm{~S}+\mathrm{N}$ & Guénée and Yvon, 2003 \\
\hline $\mathrm{Zr}_{9} \mathrm{~V}_{4} \mathrm{SD}_{23}$ & $\mathrm{P6}_{3} / m m c$ & 684 & $5+5$ & $\mathrm{~S}+\mathrm{N}$ & Zavalij et al., 2005 \\
\hline $\mathrm{ErFe}_{2} \mathrm{D}_{5}$ & $\operatorname{Pmn} 2_{1}$ & 249 & $5+8$ & $\mathrm{~N}$ & Paul-Boncour et al., 2003 \\
\hline $\mathrm{Li}_{2} \mathrm{BeD}_{4}$ & $P 2_{1} / c$ & 491 & $6+8$ & $\mathrm{X}+\mathrm{N}$ & Bulychev et al., 2004 \\
\hline $\mathrm{LaMg}_{2} \mathrm{NiD}_{7}$ & $P 2_{1} / c$ & 860 & $8+14$ & $\mathrm{~S}+\mathrm{N}$ & Renaudin et al., 2003b \\
\hline \multicolumn{6}{|c|}{ Inorganic and metalorganic compounds } \\
\hline $\mathrm{CsOH} \cdot \mathrm{H}_{2} \mathrm{O}$ & $I 4_{1} /$ amd & 297 & 2 & $\mathrm{~S}$ & Černý et al., 2002 \\
\hline $\mathrm{LiLuF}_{4}-\mathrm{HP}$ & $C 2 / c$ & 252 & 4 & $\mathrm{~S}$ & Grzechnik et al., 2005 \\
\hline $\mathrm{YK}\left(\mathrm{C}_{4} \mathrm{O}_{4}\right)_{2}$ & $P 4 / m c c$ & 448 & 4 & $\mathrm{X}$ & Mahé and Bataille, 2004 \\
\hline $\mathrm{Sn}_{2} \mathrm{P}_{2} \mathrm{O}_{7}-\mathrm{HT}$ & $P 2_{1} / n$ & 339 & 6 & $\mathrm{X}$ & Chernaya et al., 2005 \\
\hline $\left.\mathrm{Y}_{0.92} \mathrm{Er}_{0.08}\right) \mathrm{BO}_{3}-\mathrm{HT}$ & $C 2 / c$ & 728 & 9 & $\mathrm{~N}$ & Lin et al., 2004 \\
\hline $\mathrm{LiSrAlF}_{6}-\mathrm{II}$ & $P 2_{1} / c$ & 445 & 9 & $\mathrm{~S}$ & Grzechnik et al., 2004a \\
\hline $\mathrm{LiSrAlF}_{6}-\mathrm{III}$ & $P 2_{1} / c$ & 410 & 9 & $\mathrm{~S}$ & Grzechnik et al., 2004b \\
\hline $\mathrm{Dy}\left[\mathrm{Fe}(\mathrm{CN})_{6}\right] .4 \mathrm{D}_{2} \mathrm{O}$ & Cmcm & 1282 & $8+3$ & $\mathrm{~N}$ & Kavečanský et al., 2004 \\
\hline $\operatorname{Mg}_{2-x} \operatorname{Ir}_{3+x}(x=0.067)$ & $C 2 / m$ & 812 & 11 & $\mathrm{~S}$ & Černý et al., 2005 \\
\hline $\mathrm{LiB}\left(\mathrm{C}_{2} \mathrm{O}_{4}\right)_{2}$ & Pnma & 637 & 11 & $\mathrm{X}$ & Zavalij, P. Yu et al., 2003 \\
\hline $\mathrm{NaFe}_{2}(\mathrm{Mg}, \mathrm{Mn})\left(\mathrm{AsO}_{4}\right) 3 \cdot \mathrm{H}_{2} \mathrm{O}$ & $C 2 / c$ & 957 & 12 & s. cryst. & Sarp and Černý et al., 2005 \\
\hline $\mathrm{Bi}_{2} \mathrm{ZnB}_{2} \mathrm{O}_{7}$ & Pba2 & 584 & 13 & X & Barbier et al., 2005 \\
\hline $\mathrm{Th}_{2}\left(\mathrm{PO}_{4}\right)_{2}\left(\mathrm{HPO}_{4}\right), \mathrm{H}_{2} \mathrm{O}$ & $P 2_{1}$ & 502 & 18 & $\mathrm{X}$ & Salvadó et al., 2005 \\
\hline $\mathrm{CH}_{3} \mathrm{ND}_{3} \mathrm{PbCl}_{3}-\mathrm{LT}$ & Pnma & 1432 & $9+12$ & $\mathrm{~S}+\mathrm{N}$ & Chi et al., 2005 \\
\hline MgIr & Cmca & 5040 & 25 & S & Černý et al., 2004 \\
\hline $\mathrm{Al}_{2}\left(\mathrm{CH}_{3} \mathrm{PO}_{3}\right)_{3}$ & $P \overline{1}$ & 604 & $17+(9)$ & $\mathrm{X}$ & Edgar et al., 2002 \\
\hline $\mathrm{ZrP}_{2} \mathrm{FO}_{6} \mathrm{NC}_{9} \mathrm{H}_{12}$ & Pbca & 2590 & $20+(12)$ & $\mathrm{X}$ & Vivani et al., 2004 \\
\hline$\left[\mathrm{Ni}_{2} \mathrm{O}(\mathrm{L}-\mathrm{ASP})\left(\mathrm{H}_{2} \mathrm{O}\right)_{2}\right] \cdot 4 \mathrm{H}_{2} \mathrm{O}$ & $P 2_{1} 2_{1} 2_{1}$ & 2490 & 34 & $\mathrm{X}$ & Anokhina and Jacobson, 2004 \\
\hline
\end{tabular}

penalty when two atoms are closer than a minimum distance. This minimum distance can be input by the user for each pair of atom types. For identical elements, this function also allows DOC to merge the atoms (when the distance tends toward zero), so that for identical atom types which completely overlap, the penalty decreases to zero. This CF can be used for any kind of material, and only helps the algorithm to avoid improbable configurations, without affecting the position of the global minimum (at the global minimum all atoms are in a chemically sensible coordination, with the $\mathrm{AB} C \mathrm{CF}$ kept at a null value at and near the global minimum).

\section{NONMOLECULAR STRUCTURES SOLVED BY FOX}

Since its release in 2001, FOX has been quite often used for solving nonmolecular structures from powder diffraction data. They are summarized according to our best knowledge in Table I, and divided into two groups of typical applications: metal hydrides and inorganic (metalorganic) compounds. A great popularity of FOX in the metal hydride research can be understood not only because it is a main research direction in the laboratory of one of the authors, but also as a result of DOC. When hydrogen atoms are dissolved in the crystal lattice of an intermetallic compound, usually a great number of interstitial sites can be occupied by hydrogen. These sites are, however, too close to one another to be simultaneously occupied by hydrogen atoms due to their repulsive force. It leads to partially occupied hydrogen sites and uncertainty in the number of Wyckoff sites occupied by hydrogen. The DOC has shown to be an ideal tool to treat this problem, as the excess hydrogen atoms introduced to the model for the structure optimization are simply merged by DOC.

The complexity of the structures solved by FOX ranges from 2 to 34 independent atoms found $a b$ initio. In the case of metal hydrides a typical procedure applied was to solve the metal atoms substructure from X-ray or synchrotron data, and then the deuterium was located from neutron data. The exceptions are all lithium containing compounds: $\mathrm{LiBH}_{4}$ was fully characterized only with synchrotron data (see the following). In $\mathrm{Li}_{2} \mathrm{BeD}_{4}$ the beryllium and deuterium atoms were located by direct methods using program EXPO (Altomare et al., 2004) and neutron data, and lithium atoms were located by FOX with the positions of $\mathrm{BeD}_{4}$ tetrahedra 


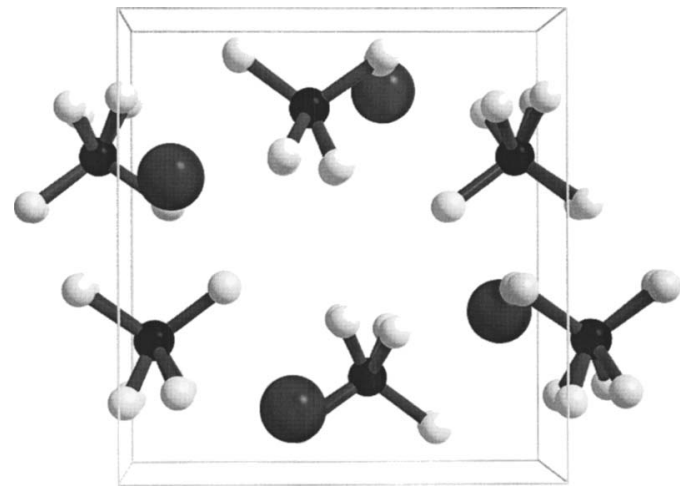

Figure 2. Orthorhombic structure (Pnma) of the room temperature phase $\mathrm{LiBH}_{4}$ modeled by one $\mathrm{BH}_{4}$ tetrahedron and one $\mathrm{Li}$ atom.

fixed using the X-ray data. On the contrary, in $\mathrm{Li}_{3} \mathrm{AlD}_{6}$ aluminum atoms were easily found from X-ray data, and then the orientation of $\mathrm{AlD}_{6}$ octahedra and position of lithium atoms were optimized by FOX using the neutron data.

In the case of inorganic and metalorganic compounds all the nonhydrogen atoms were usually located by FOX with the exception of the two $\mathrm{LiSrAlF}_{6}$ compounds where the position of lithium atoms was obtained by a comparison with a related (low pressure) compound. In $\mathrm{YK}\left(\mathrm{C}_{4} \mathrm{O}_{4}\right)_{2}$ the structure was actually solved in the space group $P 1$ due to uncertainty of the symmetry. It means that the true solution was in fact found for two yttrium and two potassium atoms, and four independent squarate groups $\mathrm{C}_{4} \mathrm{O}_{4}, 36$ atoms in total.

Decreasing the DOF by modeling the structure with larger building blocks was one of the reasons for using FOX. In many cases the tetrahedral and octahedral units were successfully used. In $\mathrm{Sn}_{2} \mathrm{P}_{2} \mathrm{O}_{7}$ two independent tetrahedral units $\mathrm{PO}_{4}$ were joined by one corner during the optimization, and correctly formed $\mathrm{P}_{2} \mathrm{O}_{7}$ pyrogroup. In the following we will give examples of the crystal structure modeling from building blocks, and discuss when such modeling increases the convergence of the structure solution procedure.

\section{A. $\mathrm{LiBH}_{4}-\mathrm{RT}$}

The room temperature structure of this light metals hydrides is the first example of a metal hydride structure for which the hydrogen atoms have been located unambiguously by X-ray synchrotron powder diffraction. Although the precision of the metal-hydrogen bond lengths obtained is lower than that usually attained by neutron diffraction, they were useful for a crystal chemical discussion. For structure analysis powder data were measured in Debye-Scherrer geometry (Swiss-Norwegian beamline, ESRF Grenoble, $\lambda$ $=0.48562 \AA$ ) to eliminate the transparency error of focusing diffraction geometries which is very disturbing for this very low absorbing compound.

The orthorhombic structure was modeled (Soulié et al., 2002) by one $\left(\mathrm{BH}_{4}\right)^{-}$anion and one $\mathrm{Li}^{+}$cation as deduced from the chemical formula, cell volume, and the multiplicity of the general Wyckoff site. The model converged within a few minutes to the correct structure. The $\left(\mathrm{BH}_{4}\right)^{-}$unit was kept as a semirigid tetrahedron with $\mathrm{B}-\mathrm{H}$ distances within the limit 1.2-1.6 $\AA$. Even if the structure is quite a simple one (Figure 2), the modeling with $\left(\mathrm{BH}_{4}\right)^{-}$building blocks rather

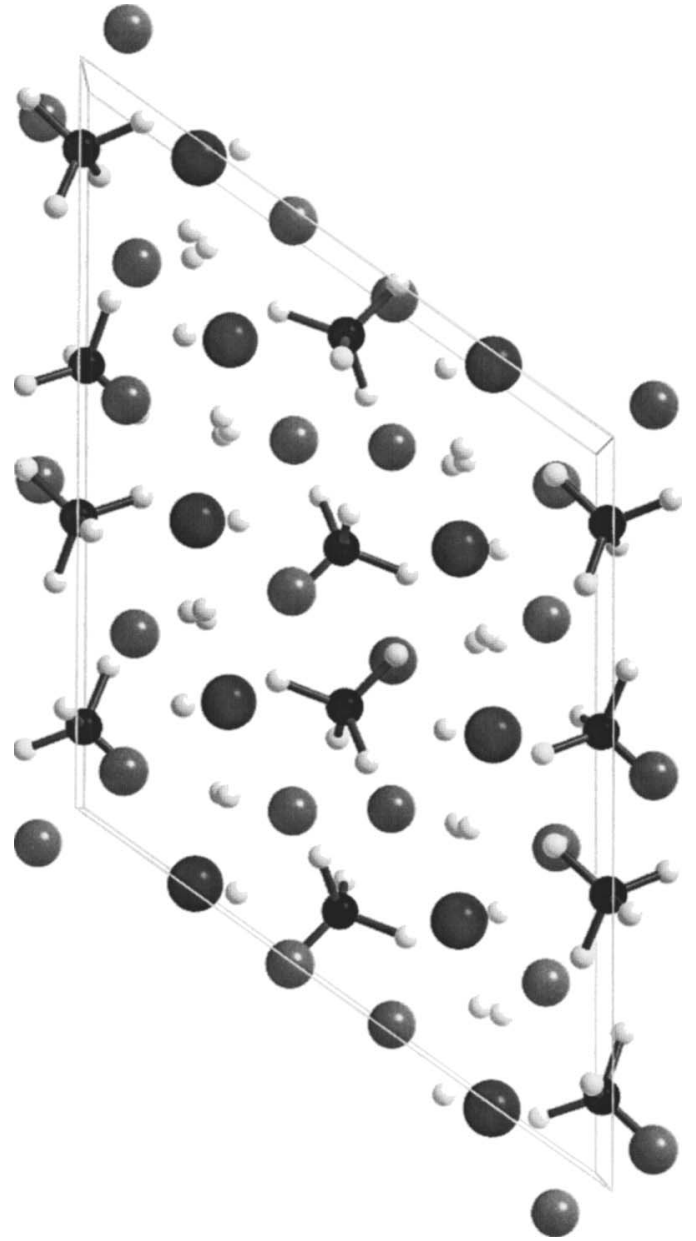

Figure 3. Monoclinic structure $\left(P 2_{1} / c\right)$ of $\mathrm{LaMg}_{2} \mathrm{NiD}_{7}$ modeled by two $\left[\mathrm{NiD}_{4}\right]$ tetrahedra, two La (dark gray), four Mg (gray), and six D (light gray) atoms.

than with five free atoms increase the convergence by a factor of 5 .

\section{B. $\mathrm{LaMg}_{2} \mathrm{NiD}_{7}$}

The structure (Figure 3) of monoclinic $\mathrm{LaMg}_{2} \mathrm{NiH}_{7}$ $\left(\mathrm{LaMg}_{2} \mathrm{NiD}_{7}\right)$ was solved and refined [Renaudin et al., 2003b] by using synchrotron and neutron powder diffraction on deuteride. The solution is an example where the correct building blocks, tetrahedral complexes $\left[\mathrm{NiH}_{4}\right]^{4-}$ were recognized only when the structure was solved by modeling with free atoms.

Synchrotron powder diffraction pattern, collected at Swiss-Norwegian beamline (BM1) at ESRF (Grenoble, France) at the wavelength $\lambda=0.49949 \AA$, was useful to elucidate real crystallographic system (small monoclinic distortion of the pseudo-orthorhombic lattice), space group, and position of metals atoms. Neutron powder diffraction pattern, collected on the deuteride sample by using the highresolution powder diffractometer D2B at ILL (Grenoble) $\lambda$ $=1.594 \AA$, was useful to locate position of deuterium atoms.

The metal atom substructure was modeled with two lanthanum, two nickel, and four magnesium free atoms that were easily located from synchrotron data. Fourteen deuterium sites in general position $4 e$ of the space group $P 2_{1} / c$ 
were located from neutron data keeping the metal atoms positions fixed, and any additional deuterium atom was merged by DOC. From subsequent optimization of the deuterium sites occupation it was found that the structure is fully ordered, and two independent $\left[\mathrm{NiD}_{4}\right]^{4-}$ complexes and six ionic deuterium atoms in the unit cell were recognized. When the optimization was run with modeling by two $\left[\mathrm{NiD}_{4}\right]$ semirigid tetrahedra with Ni-D distances within the limit 1.5-1.6 $\AA$ and six free deuterium atoms, the increase in the convergence was around three times.

\section{Mglr}

MgIr is a topologically close-packed intermetallic phase containing 13 iridium and 12 magnesium atoms in the asymmetric unit (Černý et al., 2004). Its structure was originally solved from synchrotron powder diffraction data, and then confirmed using single crystal data. The trials to solve the structure by methods using extracted integrated intensities from the powder pattern (direct methods or Patterson synthesis) have failed, probably because of difficult recognition of a structural motif in low-resolution E- or Patterson maps. Hence the modeling in direct space was successfully attempted. As CF, the integrated $R_{w}$ factor (Favre-Nicolin and Černý, 2002) and AB function (based on minimal distances $\mathrm{Mg}-\mathrm{Ir}=2.7$ and $\mathrm{Mg}-\mathrm{Mg}=2.8 \AA$ ) weighted $0.55 / 0.45$ were used.

No additional information on the coordination of iridium and magnesium atoms was available, and the coordination number in close packed phases can vary between 12 and 16 . As a consequence the structural model was built from free atoms. The crystal structure was expected to be closely packed, therefore the expected volume per atom was estimated as $15-20 \AA^{3}$ giving between 250 and 330 atoms in the unit cell. First, 11 free $\mathrm{Mg}$ atoms and 11 free Ir atoms were introduced on random positions in the cell, and DOC was used with the advantages of automatic identification of the special crystallographic positions and of merging the excess atoms. All 22 atoms were quickly localized, and from 11 positions of $\mathrm{Mg}$, two were identified by further occupancy optimization as being in fact occupied by Ir instead of Mg. In the next runs 13 already localized Ir atoms were kept fixed, and the number of free $\mathrm{Mg}$ atoms was increased in subsequent runs in steps of one until $12 \mathrm{Mg}$ atoms were localized, and all the additional $\mathrm{Mg}$ atoms introduced into the model were systematically merged by the program. In a final run (repeated many times) $13 \mathrm{Ir}$ and $12 \mathrm{Mg}$ free atoms were optimized simultaneously (75 DOF), and the same solution was always found in less than $5 \mathrm{~min}$.

The final structure (Figure 4) can be built from seven icosahedra centered by iridium with different ratio between magnesium and iridium atoms as ligands. Consequently a modeling with seven rigid icosahedra was attempted lowering the DOF down to 42 . Nevertheless the convergence of this modeling was much slower ( $\sim$ ten times), clearly due to the fact that the icosahedra are not ideal (central atom-ligand distance varying between 2.45 and $3.52 \AA$ ) and due to the problems with ligand identification. If the identification is done by the optimization algorithm using the random change

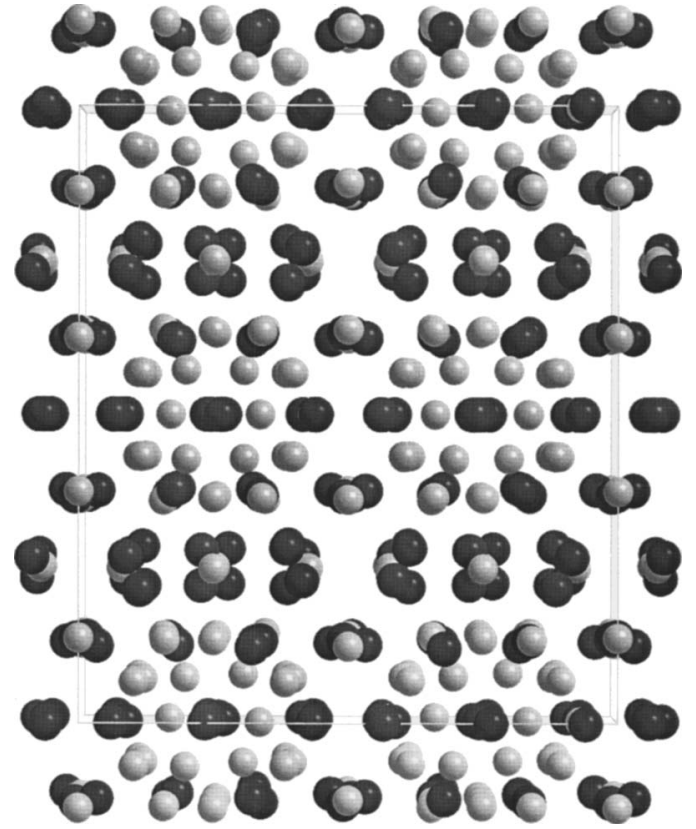

Figure 4. Orthorhombic ( $\mathrm{Cmca}$ ) structure of MgIr modeled by 13 Ir (light gray) and $12 \mathrm{Mg}$ (dark gray) atoms.

"swapping," the DOF increases by 12 per icosahedron, and no considerable increase in the optimization convergence was achieved.

\section{Yazganite, $\mathrm{NaFe}_{2}(\mathrm{Mg}, \mathrm{Mn})\left(\mathrm{AsO}_{4}\right) \mathbf{3} \cdot \mathrm{H}_{2} \mathrm{O}$}

Yazganite, a new mineral, is an example of solving the crystal structure when the chemical composition is not exactly known (Sarp and Černý, 2005). The exact ratio between the content of $\mathrm{As}^{5+}, \mathrm{Fe}^{3+}, \mathrm{Mg}^{2+}$, and $\mathrm{Mn}^{2+}$ cations was not known with sufficient precision which would allow us to write a stoichiometric formula. As the DOC working in FOX allows merging not only of excess free atoms but even of whole building blocks like coordination polyhedra, we have used FOX to solve the structure of yazganite even though the single crystal data were available. The direct methods using the single crystal data have not provided the correct solution when the wrong crystal composition was introduced.

The starting model for the structure optimization with FOX contained three $\mathrm{AsO}_{4}$ tetrahedra, with two $\mathrm{FeO}_{6}$ and one $\mathrm{MnO}_{6}$ octahedron. The correct structure has only two $\mathrm{AsO}_{4}$ tetrahedra, with one $\mathrm{FeO}_{6}$ and one $(\mathrm{Mg}, \mathrm{Mn}) \mathrm{O}_{6}$ octahedron. The excessive $\mathrm{AsO}_{4}$ tetrahedron and $\mathrm{FeO}_{6}$ octahedron were successfully merged with their respective equivalents. The structure optimization has converged within 10 min (Figure $5)$.

\section{E. $\mathrm{Al}_{2}\left(\mathrm{CH}_{3} \mathrm{PO}_{3}\right)_{3}$}

Metalorganic solids, such as metal phosphonates and carboxylates, can crystallise to give coordination polymers or inorganic layer or framework structures lined with organic groups. The structures of these materials can be considered in terms of linked, well-defined, building units. For metal phosphonates these units are the phosphonate anions, metal cations, and additional species (such as hydroxyl groups or water molecules) that may be bound to the metal cations or 


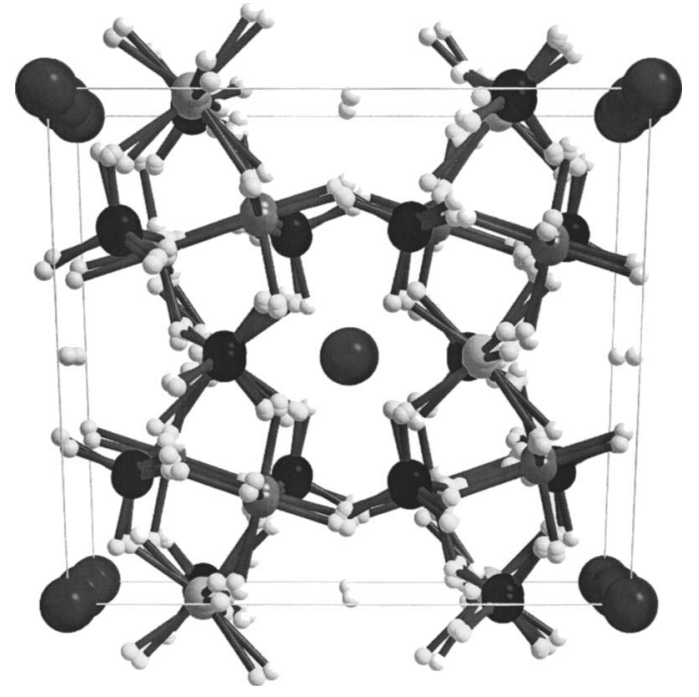

Figure 5. Monoclinic $(C 2 / c)$ structure of yazganite modeled by three $\mathrm{AsO}_{4}$ tetrahedra, two $\mathrm{FeO}_{6}$ and one $\mathrm{MnO}_{6}$ octahedra, one $\mathrm{Na}$ (dark gray) atom and one $\mathrm{O}$ (light gray) atom of the water molecule.

occluded within the pore space. This "building block" composition makes these materials ideal candidates for the structural solution by the direct space method.

Solid state ${ }^{27} \mathrm{Al}$ MAS NMR spectroscopy of the AlMePO- $\gamma$ phosponate identified two aluminum signals characteristic of tetrahedrally and fivefold coordinated aluminum, respectively. The ${ }^{31} \mathrm{P}$ MAS NMR spectrum revealed three signals of equal intensity that correlate to three signals observed in the ${ }^{13} \mathrm{C}$ NMR spectrum, indicating the presence of three crystallographically inequivalent $\mathrm{CH}_{3} \mathrm{PO}_{3}$ units. Two different modelings of the AlMePO- $\gamma$ structure from building blocks were then possible:

(1) From three $\mathrm{CPO}_{3}$ fragments and two free aluminum atoms.

(2) From one $\mathrm{AlO}_{4}$ tetrahedron, $\mathrm{AlO}_{5}$, one trigonal bipyramid, and three C-P units.

Surprisingly, even if both models have similar DOF (24 and 27 for the first and the second model, respectively) and the second model exploits better the NMR information on the aluminum coordination, the first model (Figure 6) converged nearly ten times faster to the correct solution (Edgar et al., 2002). The reason is evidently in different shapes of the hypersurface in the parameter space. In the case of the second model the hypersurface must contain more local minima of similar depth due to lower diffraction contrast between $\mathrm{AlO}_{4}$ and $\mathrm{AlO}_{5}$ building blocks.

\section{FUTURE DEVELOPMENTS OF FOX}

Future development of FOX do not depend only on its authors, but also as an open source program, in addition to any user who decides on modifications. Those planned by us are oriented mainly toward increasing the efficiency of the global optimization by adding additional crystalo-chemical information to the total cost function and by improving the optimization algorithm:

(1) Introducing energy criteria is difficult, because models

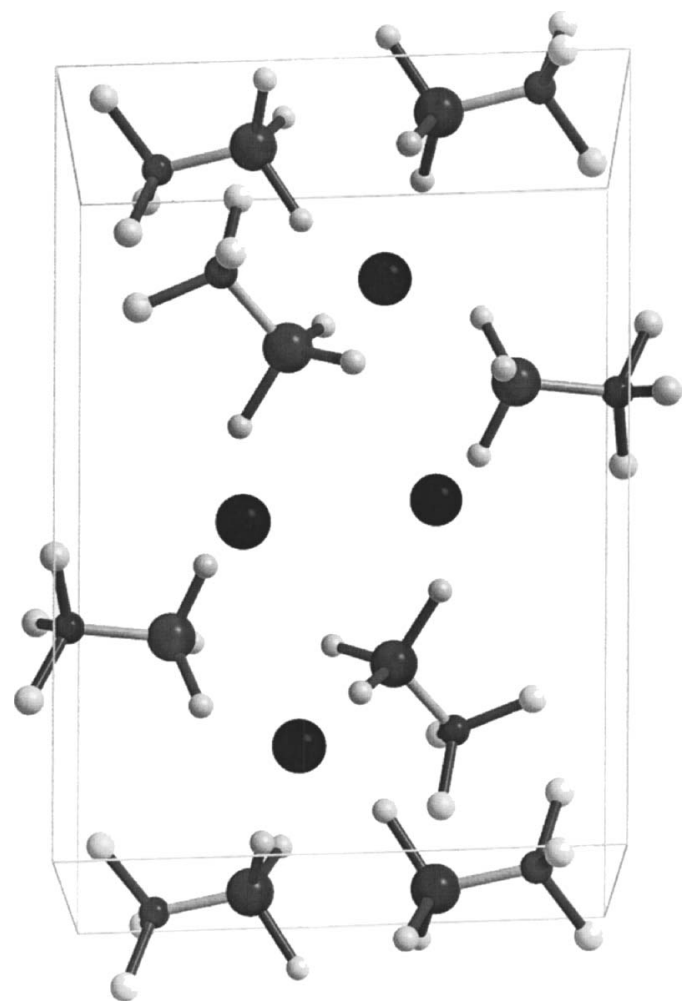

Figure 6. Triclinic $(P \overline{1})$ structure of AlMePO- $\gamma$ phosponate modeled by three $\mathrm{CPO}_{3}$ molecules and two $\mathrm{Al}$ atoms.

vary with the type of structure, and FOX should remain flexible. Tests are currently performed (Smrčok and Matěj, 2005) on inorganic compounds with modeling the lattice electrostatic energy by Ewald sum [Ewald 1921].

(2) Cost function based on bond valence sum (Pannetier $e t$ al., 1990) seems to be a good option for testing the validity of found structural models, and identifying the local minima in the parameter space. Its effect on improving the convergence of the optimization algorithm is currently tested by us.

(3) Intermolecular restraints which exploit the information available from the NMR spectroscopy data will certainly improve the efficiency of the optimization for molecular crystals.

(4) Further studies are planned on the use of maximum likelihood principle to actively use the information about the errors of the structural model.

(5) The optimization algorithm will include the derivative calculations which open the implementation of other algorithms that use it actively (hybrid Monte Carlo, algorithms performing local minimization, etc.).

(6) The structure factors will be extracted from the diffraction data, whenever possible, and Fourier maps will be calculated to detect atoms in wrong positions, to calculate structural envelopes, etc.

Other improvements include enlarging the capabilities of FOX, such as supporting time of flight neutron diffraction data and modeling of pair distribution function, whose active use in the structure solution process will also be studied. 


\section{CONCLUSIONS}

The modeling of nonmolecular crystal structures from larger building blocks improves the convergence of the global optimization algorithm by a factor of up to 10 . However, care must be taken about the correctness of the building block like its rigidity, deformation, bonding distances, and ligand identity. The errors in building blocks should be treated with the maximum likelihood approach.

Dynamical occupancy correction as implemented in FOX successfully merges the excess atoms and even larger building blocks like coordination polyhedra. It also allows joining smaller blocks (polyhedra) into larger ones when it is not a priori evident from the structural model.

\section{ACKNOWLEDGMENTS}

The authors want to thank all users of FOX, and especially those who have kindly provided us the details of their work when solving crystal structures.

Altomare, A., Caliandro, R., Camalli, M., Cuocci, C., Giacovazzo, C., Moliternia, A. G. G., and Rizzi, R. (2004). "Automatic structure determination from powder data with EXPO2004," J. Appl. Crystallogr. 37, $1025-1028$.

Anokhina, E. V. and Jacobson, A. J. (2004). " $\left[\mathrm{Ni}_{2} \mathrm{O}(\mathrm{L}-\mathrm{ASP})\right.$ $\left.\times\left(\mathrm{H}_{2} \mathrm{O}\right)_{2}\right] \cdot 4 \mathrm{H}_{2} \mathrm{O}$ : A homochiral 1D helical chain hybrid compound with extended Ni-O-Ni bonding," J. Am. Chem. Soc. 126, 3044-3045.

Barbier, J., Penin, N. and Cranswick, L. M. (2005). "Melilite-type borates $\mathrm{Bi}_{2} \mathrm{ZnB}_{2} \mathrm{O}_{7}$ and $\mathrm{CaBiGaB}_{2} \mathrm{O}_{7}$," Chem. Mater. 17, 3130-3136.

Brinks, H. W. and Hauback, B. C. (2003). "The structure of $\mathrm{Li}_{3} \mathrm{AlD}_{6}$," J. Alloys Compd. 354, 143-147.

Bulychev, B. M., Shpanchenko, R. V., Antipov, E. V., Sheptyakov, D. V., Bushmeleva, S. N., and Balagurov, A. M. (2004). "Synthesis and crystal structure of lithium beryllium deuteride $\mathrm{Li}_{2} \mathrm{BeD}_{4}$," Inorg. Chem. 43, 6371-6376.

Černý, R., Favre-Nicolin, V., and Bertheville, B. (2002). "A tetragonal polymorph of caesium hydroxide monohydrate, $\mathrm{CsOH} . \mathrm{H}_{2} \mathrm{O}$, from X-ray powder data," Acta Crystallogr., Sect. A: Found. Crystallogr. 58, i31i32.

Černý, R., Renaudin, G., Favre-Nicolin, V., Hlukhyy, V., and Pöttgen, R. (2004). " $\mathrm{Mg}_{1+x} \mathrm{Ir}_{1-x}(x=0,0.037$ and 0.054$)$, a binary intermetallic compound with a new orthorhombic structure type determined from powder and single-crystal X-ray diffraction," Acta Crystallogr., Sect. B: Struct. Sci. 60, 272-281.

Černý, R., Renaudin, G., Tokaychuk, Ya., and Favre-Nicolin, V. (2005). "Complex intermetallic compounds in the $\mathrm{Mg}$-Ir system solved by powder diffraction," Z. Kristallogr. (in press).

Chernaya, V. V., Mitiaev, A. S., Chizhov, P. S., Dikarev, E. V., Shpanchenko, R. V., Antipov, E. V., Korolenko, M. V., and Fabritchnyi, P. B. (2005). "Synthesis and investigation of tin(II) pyrophosphate $\mathrm{Sn}_{2} \mathrm{P}_{2} \mathrm{O}_{7}$," Chem. Mater. 17, 284-290.

Chi, L., Swainson, I., Cranswick, L., Her, J.-H., Stephens, P., and Knop, O. (2005). "The ordered phase of methylammonium lead chloride $\mathrm{CH}_{3} \mathrm{ND}_{3} \mathrm{PbCl}_{3}$," J. Solid State Chem. 178, 1376-1385.

David, W. I. F., Shankland, K., McCusker, L. B., and Baerlocher, Ch. (2002). Structure Determination from Powder Diffraction Data (Oxford University Press, Oxford) IUCr. Monographs on Crystallography 13.

Edgar, M., Carter, V. J., Tunstall, D. P., Grewal, P., Favre-Nicolin, V., Cox, P. A., Lightfoot, P., and Wright, P. A. (2002). "Structure solution of a novel aluminum methylphosphonate using a new simulated annealing program and powder X-ray diffraction data," Chem. Commun. (Cambridge) 8, 808-809. Emald, P. P. (1921). Ann. Phys 64, 253.

Favre-Nicolin, V. and Černý, R. (2002). "FOX, 'Free Objects for Crystallography:' A modular approach to ab initio structure determination from powder diffraction," J. Appl. Crystallogr. 35, 734-743.

Favre-Nicolin, V. and Černý, R. (2004). "A better FOX: Using flexible modelling and maximum likelihood to improve direct-space ab initio structure determination from powder diffraction," Z. Kristallogr. 219, 847856.
Grzechnik, A., Dmitriev, V., Weber, H. P., Gesland, J. Y., and van Smaalen, S. (2004a). "The crystal structures of pressure-induced LiSrAlF $_{6}-\mathrm{II}$ and LiCaAlF$_{6}$-II," J. Phys.: Condens. Matter 16, 1033-1043.

Grzechnik, A., Dmitriev, V., Weber, H. P., Gesland, J. Y., and van Smaalen, S. (2004b). "LiSrAlF 6 with the $\mathrm{LiBaCrF}_{6}$-type structure," J. Phys.: Condens. Matter 16, 3005-3013.

Grzechnik, A., Friese, K., Dmitriev, V., Weber, H. P., Gesland, J. Y., and Crichton, W. A. (2005). "Pressure-induced tricritical phase transition from the scheelite structure to the fergusonite structure in $\mathrm{LiLuF}_{4}$," J. Phys.: Condens. Matter 17, 763-770.

Guénée, L., Favre-Nicolin, V., and Yvon, K. (2003). "Synthesis, crystal structure and hydrogenation properties of the ternary compounds $\mathrm{LaNi}_{4} \mathrm{Mg}$ and $\mathrm{NdNi}_{4} \mathrm{Mg}$," J. Alloys Compd. 348, 129-137.

Guénée, L. and Yvon, K. (2003). "Synthesis, crystal structure and hydrogenation properties of the novel metal compound $\mathrm{LaNi}_{2} \mathrm{Mn}_{3}$," J. Alloys Compd. 348, 176-183.

Kavečanský, V., Mihalik, M., Mitróová, Z., and Lukáčová, M. (2004). "Neutron diffraction study of crystal and magnetic structure of Dy $\left[\mathrm{Fe}(\mathrm{CN})_{6}\right] .4 \mathrm{D}_{2} \mathrm{O}$," Czech. J. Phys. 54, D571-D574.

Lin, J., Sheptyakov, D., Wang, Y., and Allenspach, P. (2004). "Structures and phase transition of vaterite-type rare earth orthoborates: A neutron diffraction study, $\left[\mathrm{Y}_{0.92} \mathrm{Er}_{0.08}\right) \mathrm{BO}_{3}$," Chem. Mater. 16, 2418-2424.

Mahé, N. and Bataille, T. (2004). "Synthesis, crystal structure from singlecrystal and powder X-ray diffraction data, and thermal behavior of mixed potassium lanthanide squarates: Thermal transformations of layered $\left[\mathrm{Ln}\left(\mathrm{H}_{2} \mathrm{O}\right)_{6}\right] \mathrm{K}\left(\mathrm{H}_{2} \mathrm{C}_{4} \mathrm{O}_{4}\right)\left(\mathrm{C}_{4} \mathrm{O}_{4}\right)_{2}$ into pillared $\mathrm{LnK}\left(\mathrm{C}_{4} \mathrm{O}_{4}\right)_{2}$ ( $\mathrm{Ln}$ $=\mathrm{Y}, \mathrm{La}, \mathrm{Gd}, \mathrm{Er})$, , Inorg. Chem. 43, 8379-8386.

Newsam, J. W., Deem, M. W., and Freeman, C. M. (1992). "Direct space methods of structure solution from powder diffraction data," NIST Spec. Publ. 846, 80-91.

Pannetier, J., Bassas-Alsina, J., Rodriguez-Carvajal, J., and Caignaert, V. (1990). "Prediction of crystal structures from crystal chemistry rules by simulated annealing," Nature (London) 346, 343-345.

Paul-Boncour, V., Filipek, S. M., Marchuk, I., André, G., Bourée, F., Wiesinger, G., and Percheron-Guégan, A. (2003). "Structural and magnetic properties of $\mathrm{ErFe}_{2} \mathrm{D}_{5}$ studied by neutron diffraction and Mössbauer spectroscopy," J. Phys.: Condens. Matter 15, 4349-4359.

Renaudin, G., Bertheville, B., and Yvon, K. (2003a). "Synthesis and structure of an orthorhombic low-pressure polymorph of caesium magnesium hydride, $\mathrm{CsMgH}_{3}$," J. Alloys Compd. 353, 175-179.

Renaudin, G., Guénée, L., and Yvon, K. (2003b). " $\mathrm{LaMg}_{2} \mathrm{NiH}_{7}$, a novel quaternary metal hydride containing tetrahedral $\left[\mathrm{NiH}_{4}\right]^{4-}$ complexes and hydride anions," J. Alloys Compd. 350, 145-150.

Salvadó, M. A., Pertierra, P., Bortun, A. I., Trobajo, C., and García, J. R. (2005). "New hydrothermal synthesis and structure of $\mathrm{Th}_{2}\left(\mathrm{PO}_{4}\right)_{2}\left(\mathrm{HPO}_{4}\right) \cdot \mathrm{H}_{2} \mathrm{O}$ : The first structurally characterized thorium hydrogenphosphate," Inorg. Chem. 44, 3512-3517.

Sarp, H. and Černý, R. (2005). "Yazganite, $\mathrm{NaFe}_{2}^{3+}(\mathrm{Mg}, \mathrm{Mn})\left(\mathrm{AsO}_{4}\right)_{3} \cdot \mathrm{H}_{2} \mathrm{O}$, a new mineral: Its description and crystal structure," Eur. J. Mineral. 17, 367-373.

Shankland, K. (2004). "Whole molecule constraints-the Z-matrix unraveled," Newsletter of the Commission on Crystallographic Computing of the International Union of Crystallography, No. 4, pp. 46-51, see also: http://www.iucr.org/iucrtop/comm/ccom/newsletters/2004aug/index.html

Shankland, K., David, W. I. F., and Csoka, T. (1997). "Crystal structure determination from powder diffraction data by the application of a genetic algorithm," Z. Kristallogr. 212, 550-552.

Smrčok, L. and Matěj, Z. (2005). Private communication.

Soulié, J.-Ph., Renaudin, G., Černý, R., and Yvon, K. (2002). "Lithium boro-hydride, $\mathrm{LiBH}_{4}$ : I. Crystal structure," J. Alloys Compd. 346, 200205.

Vivani, R., Costantino, F., Nocchetti, M., and Gatta, G. D. (2004). "Structural homologies in benzylamino- $N, N$-bis methylphosphonic acid and its layered zirconium derivative," J. Solid State Chem. 177, 4013-4022.

Zavalij, I. Yu., Černý, R., Koval'chuck, I. V., Riabov, A. B., and Denys, R. V. (2005). "Synthesis and crystal structure of $\kappa-\mathrm{Zr}_{9} \mathrm{~V}_{4} \mathrm{SH}_{23.5}$ hydride," J. Alloys Compd.. (in press).

Zavalij, I. Yu., Černý, R., Koval'chuck, I. V., and Saldan, I. V. (2003). "Hydrogenation of oxygen-stabilized $\mathrm{Zr}_{3} \mathrm{NiO}_{x}$ compounds," J. Alloys Compd. 360, 173-182.

Zavalij, P. Yu., Yang, S., and Whittingham, M. S. (2003). "Structures of potassium, sodium and lithium bis(oxalato)borate salts from powder diffraction data," Acta Crystallogr., Sect. B: Struct. Sci. 59, 753-759. 